\title{
Limites e potencialidades do Desenvolvimento Regional
}

\author{
Sandro Luiz Bazzanella ${ }^{1}$ \\ Felipe Onisto ${ }^{2}$
}

\section{Resumo}

O presente artigo discute as potencialidades e limites do desenvolvimento regional perante os limites e as possibilidades do Estado contemporâneo, da cultura local e do processo de globalização. O texto se desdobra em cinco eixos: 1ํ․ Problemáticas do Desenvolvimento Regional: limites e potencialidades; 2 : : Critérios do desenvolvimento regional à luz de Sergio Boisier; 3: Limites e potencialidades do desenvolvimento perante o processo de globalização; 4ํ: Construção política do desenvolvimento: participação social e 5o: Desenvolvimento regional diante das Políticas Públicas. Seu objetivo é relacionar conceitos e práticas que possibilitam ou dificultam o desenvolvimento regional. O método utilizado na pesquisa é, num primeiro momento, de caráter bibliográfico revisionista, amparado pela modalidade teórica. Desta forma, permite ampliar as discussões e generalizar os escritos elencados. A partir da pesquisa exploratória, foi favorável o levantamento bibliográfico, necessário ao ensaio. A base de dados se estruturou em fontes primárias e secundárias. Num segundo momento, a abordagem técnico-qualitativa prevaleceu nas análises, imperativa do método dedutivo. Os resultados alcançados foram as convergências e divergências encontradas para a promoção do desenvolvimento regional à luz de acontecimentos econômicos, políticos, ambientais e culturais contemporâneos. Frente aos estudos realizados, considera-se que não há um caminho certo que propicie o desenvolvimento, e, sim, relações de caráter endógeno e exógeno que facilitam seu alcance.

Palavras-chave: Desenvolvimento Regional. Participação Social. Políticas Públicas.

\section{Abstract}

This article discusses the potential and limits of regional development before the limits and possibilities of the contemporary state, local culture and the globalization process. The text unfolds in five areas: 1. Issues of Regional Development : Limits and potentialities; 2 Criteria for regional development in the light of Sergio Boisier; 3

${ }^{1}$ Graduado em Filosofia (FFCLDB/RS - 1989). Mestrado em Educação e Cultura (UDESC - 2003). Doutor em Ciências Humanas (UFSC - 2010). Professor de Filosofia e Coordenador do Programa de Mestrado em Desenvolvimento Regional da Universidade do Contestado - Campus Canoinhas. Líder do Grupo de Pesquisa Interdisciplinar em Ciências Humanas (Cnpq) e do Grupo de Estudo em Giorgio Agamben (GEA) - www.agambenbrasil.com.br. sandroluizbazzanella@gmail.com

2 Graduado em Ciências Sociais pela Universidade do Contestado - UnC - Canoinhas - SC, PósGraduação em Gestão Pública pela UFSC (Universidade Federal de Santa Catarina). Atua como professor e coordenador do curso de graduação de Ciências Sociais da Universidade do Contestado - UnC. feonisto@gmail.com 
Limits and potentialities of development before the process of globalization ; 4 Construction of the development policy : social and 5th Regional Development on Public Policy participation. Your goal is to relate the concepts and practices that enable and constrain regional development. The method used in the research is at first revisionist bibliographical character, supported by the theoretical method. This way allows to extend and generalize the discussions listed writings. From the exploratory research was favorable the literature review required by the assay. The database is structured in primary and secondary sources. Secondly, qualitative approach prevailed in technical analysis, overriding the deductive method. The results shows the convergences and divergences found to promote regional development in the light of contemporary economic developments, political, environmental and cultural. Front to studies, it is considered that there is a certain way that enables the development and relationships rather endogenous and exogenous nature that facilitate your fingertips.

Keywords: Regional Development. Social Participation. Public Policy.

\section{Problemáticas do Desenvolvimento Regional: limites e potencialidades}

O presente artigo discute o conceito de Desenvolvimento Regional, amparado nos pressupostos teóricos de Sergio Boisier ${ }^{3}$. Sua estruturação resulta de dois textos: "Em busca do esquivo desenvolvimento regional: entre a caixa-preta e o projeto político" (1996), e "El dessarolo territorial a partir de la construccion de capital sinergético" (1999).

Segundo o teórico, existem três cenários que são interdependentes e levam a identificar o Desenvolvimento Regional hodiernamente: cenário contextual, cenário estratégico e cenário político.

O cenário contextual apresenta dois fenômenos modernos: abertura externa dos países, forçada pela globalização (fator predominantemente econômico), seguida da abertura interna, ocasionada pelas primazias da descentralização (atividade de caráter político). O processo de unificação mundial permite mensurar as regiões que melhor se posicionam na cena mundial frente a índices pré-

\footnotetext{
${ }^{3}$ Engenheiro comercial (economista) da Universidade de Chile. Master of Arts in Regional Science, Universidade de Pensilvânia, USA. Phd em Economia Aplicada, Universidade de Alcalá, Henares, Espanha. Atualmente, atua como consultor internacional independente e presidente do Centro de Análise e Ação Território e Sociedade (CATS), consultora privada. É professor visitante da Universidade dos Lagos, Universidade Austral de Chile, Universidade da Fronteira Nacional San Martín, Buenos Aires, Argentina. Membro do Conselho Assessor e do Conselho Consultivo Internacional do Magíster em Desenvolvimento Humano e Escala Local e Regional, Universidade da Fronteira, Chile.
} 
estabelecidos. O PIB e a Balança Comercial destacam-se pela produção de elementos em comum e ligação à lógica, que sustenta o espaço economicamente. Nesses casos, as medições dos espaços regionais não são por limites naturais ou construídos, mas levam em consideração a produção local: economia, cultura, política, e definição dos limites territoriais.

A descentralização política e administrativa dos governos outorga, à participação social nos processos decisórios, uma maneira de elevar a sua qualidade de vida. O Estado descentralizado facilita a resolubilidade dos processos reivindicativos que demandam das regiões in locu, regra que proporciona desenvolvimento econômico e distribuição de renda. Segundo Affonso (2000, p. 3): "a possibilidade de superar o atraso econômico na América Latina e vincular o desenvolvimento econômico ao desenvolvimento social dependeria, em grande parte, da descentralização do aparelho de Estado".

Promover a participação civil e empresarial incentiva as inovações tecnológicas e científicas, o que oportunizará maior competitividade às empresas e tornará as políticas públicas medidas que atendam às peculiaridades regionais. A racionalidade estatal e seu poder financeiro permitem ao Estado elaborar pesquisas no rumo de descobrir produtos, ou aperfeiçoar ideias que outrora estiveram amparadas nos conhecimentos familiares.

Descentralizar o Estado é sinônimo de eficiência popular. Compartilhar as responsabilidades nos processos decisórios torna o povo ativo politicamente. $O$ fenômeno é estratégico para diminuir a burocracia e acelerar a mediação dos governos na promoção do desenvolvimento democrático.

No cenário estratégico, as regiões se dividem em três conceitos: regiões pivotais, regiões associativas e regiões virtuais. A área pivotal compõe um menor número de territórios, seus membros têm alta capacidade na resolução de problemáticas, seus traços culturais são sistematicamente complexos; entretanto, extremamente coercitivos na geração de novas identidades. Essas regiões podem se unir, para formar a região associativa, extensão maior geograficamente, semelhante nos traços sociais. As localidades tornam-se amplas, quando sintonizadas em regiões virtuais, ou melhor, através de redes que se constituem para produção de interações nos mercados regionais. 
No cenário político, Boisier analisa a ideia das regiões se relacionarem diante do cenário da dominação e dependência. Os dominadores detêm o privilégio do posicionamento político, nas tomadas de decisões, coagindo os oprimidos, quando investido capital econômico nas regiões menos desenvolvidas. Segundo a lógica financeira, trata-se de investimento, requerendo lucro, este processo torna a região dependente nas cadeias produtivas. A condição se agrava pela ausência de autonomia nos setores, sustentada pela centralidade política, visto que o eixo atende à condição do capital externo. Perante a leitura, cabe a indagação: $O$ que resta às regiões menos desenvolvidas? Segundo Boisier (1996, p. 16):

Isso é resolvido mediante dois processos: o primeiro, pela transferência de
poder político incorporada em um projeto nacional descentralizador (como o
que opera com timidez o Chile e com algo mais de audácia, pelo menos
financeira, a Colômbia), e segundo, por meio da criação de poder político,
algo que se obtém mediante o consenso político, o pacto social, a cultura da
cooperação e a capacidade de criar, coletivamente, um projeto de
desenvolvimento. Eis, portanto, a relevância do conceito de projeto político
regional como instrumento de criação de poder político.

Sob tais pressupostos, pode-se considerar que região oeste do estado de Santa Catarina demonstra de forma mais intensa esses fatores (políticos e cooperativos) resultantes do processo de colonização e de incentivos governamentais. O pesquisador em desenvolvimento rural Oscar Rover, em seu artigo: "Gestão política e desenvolvimento na região oeste de Santa Catarina" (2009), demonstra a importância histórica do Estado como protagonista na promoção do desenvolvimento regional, atuando como promotor de políticas públicas.

O referido artigo divide a região de maneira cronológica. Primeiro no processo de colonização exercido pelos europeus, no início do século $X X$, seguido da colonização entre as décadas de 1917 a 1960. A terceira fase refere-se à modernização da agricultura, instaurada durante o período do milagre econômico, vivenciado pelo país na década de 1970, e finaliza com o período contemporâneo, marcado pela crise pós-milagre econômico, latentes as características da descentralização do Estado e constituição de programas sociais, como o Programa Nacional de Fortalecimento da Agricultura Familiar - PRONAF.

"Dos quatro períodos relatados, à exceção do primeiro, no qual não se identifica a presença clara do Estado na região oeste catarinense, nos outros três ele 
é o principal ator que condiciona os processos de desenvolvimento regional" (ROVER, 2009, p.113).

A intervenção estatal, nos períodos estudados, possibilitou a modernização do trabalho e facilitou o crédito. Porém, no setor político, as práticas se tornavam insustentáveis perante a centralidade do Regime Militar, antidemocrático. A contemporaneidade, sobretudo nas décadas após a saída do regime militar e a abertura política, permitiu a participação popular na execução de programas sociais, que levaram em consideração as necessidades da população brasileira e, naquele caso específico, da comunidade regional do oeste catarinense.

\section{Critérios do Desenvolvimento Regional à luz de Sergio Boisier}

Segundo as teorias de Boisier, são possíveis nove dimensões que se apresentam como fundamentais para as regiões que almejam o desenvolvimento regional, setorizadas na modalidade de "capital", as quais serão colocadas em jogo hodiernamente. Dentre as modalidades, o capital sinergético se destaca como o de maior relevância, possível às sociedades civis organizadas.

Sugiero denominar 'capital sinergético' a la capacidad social, o mejor, a la
capacidade 'societal' (como expresión más totalizante) de promover
acciones en conjunto dirigidas a fines colectiva y 'democráticamente'
aceptados, con el conocido resultado de obtenerse así un producto final que
es mayor que la suma de los componentes. Se trata de una capacidade
normalmente latente en toda sociedad organizada. Como toda forma de
capital, el capital sinergético es un 'stock' de magnitud determinada en
cualquier territorio y tiempo, que puede recibir flujos de energía que
aumentan este 'stock' y del cual fluyen otros flujos de energía dirigidos
precisamente a articular otras varias formas de capital. La idea de
reproducción es inseparable del concepto de capital (BOISIER, 1999, p. 42).

A sinergia liga-se à capacidade de articulação social com fins na promoção de um produto que seja capaz de conduzir o desenvolvimento. O modelo se caracteriza pela junção do Estado com a sociedade civil. Porém, o paradigma estatal deve ser descentralizado e fomentar as ações populares. Seu agir estrutural é na condição de mediador, fator imprescindível para o aprimoramento de políticas públicas. Segundo Boisier (1999), sem a participação e condução do Estado, os países em desenvolvimento não detêm capacidade de industrializar-se, fator imprescindível 
para o desenvolvimento econômico e, consequentemente, a elevação na qualidade de vida almejada pelas regiões.

O primeiro capital apresentado por Boisier é o "Capital Econômico", forma exógena de fomentar crescimento às regiões. As demandas do capital acompanham a lógica da globalização, possível sob a vertente da livre concorrência dos mercados, resultado de intervenções estatais fomentadoras, inversas aos marcos regulatórios. Ao Estado resta atuar no direcionamento dos recursos financeiros oriundos dos investidores; destarte, o capital econômico torna-se superior aos direcionamentos políticos, prerrogativa que sugere sua capacidade imanente em potencializar a distribuição de renda através da oferta de empregos e consumo.

Essa aptidão autorregulatória é antinômica, ao remontar as crises cíclicas que o sistema econômico vigente apresentou. No horizonte Marxista, o momento representa a contradição capital versus trabalho e o caminho para uma possível implosão do sistema. Os Keynesianos vislumbram a intervenção estatal como medida paliativa para o retorno gradual da livre concorrência dos mercados.

A segunda posição é ocupada pelo "Capital Cognitivo", revelador do conhecimento técnico e científico local e linear no entendimento das dinâmicas sociais.

\footnotetext{
Este stock dista de ser uniforme; por el contrario, es de elevada variedad si se entiende que incluye, primeramente, el conocimiento acerca del propio territorio (su geografía, pero sobre todo, su historia, entendida y no meramente relatada) y en seguida, una serie de 'saberes' científicos y tecnológicos susceptibles de ser usados en los procesos de crecimiento y de desarrollo, por ejemplo, conocimientos acerca de los ciclos tecnológicos que se pueden desarrollar a partir de los recursos naturales de la región (BOISIER, 1999, p. 44).
}

A produção técnico/científica capaz de compreender o ambiente emerge da racionalidade, potencial na promoção do desenvolvimento. Desvendar os fenômenos presentes, através dos resgates históricos, é condição sine qua non para pensar a condição futura e os níveis de desenvolvimento humano almejados.

Desde o reconhecimento da ciência moderna, no século XVII, a modalidade restringiu-se a países em desenvolvimento econômico. A realidade se modifica após a Segunda Guerra Mundial, com a criação das agências multilaterais e a abertura das fronteiras pela globalização financeira. Nasce, então, o capital especulativo, e 
dissemina-se o conhecimento científico aos países subdesenvolvidos e em desenvolvimento.

Nesta perspectiva, é necessário interpretar o conhecimento através da história. A partir de pressupostos da filosofia da história de fundo hegeliano, segundo Auguste Comte (1973), existem três estágios pelo quais transitam civilizações, povos e comunidades: o estágio Metafísico, o estágio Filosófico e o Positivo/Científico. Para o Pai da Sociologia, a última etapa simboliza o ápice. As formas de perceber o mundo sempre estiveram ligadas às transformações radicais nos meios políticos, econômicos, religiosos e sociais, resultantes de revoluções militares ou civis.

A temática do terceiro, o "Capital Simbólico", tem sua origem nos escritos do sociólogo francês Pierre Bourdieu (1930-2002). Segundo Boisier, as palavras agem como poder de consagração e revelação. Esse capital liga-se à produção técnico/científica e possibilita a construção da imagem local. Sua metáfora com o evangelho de João imprime a importância da palavra; na passagem bíblica, cita-se: "No princípio era o verbo". Para o teórico, essa é a origem do capital simbólico. Reconhecer a importância da palavra no processo de humanização torna-se basilar na constituição de uma sociedade estruturada em princípios de qualidade de vida. Amparado nos pressupostos filosóficos possíveis, a palavra é "arché", potência para consolidação do desenvolvimento regional.

O "Capital Cultural" ampara-se nas produções materiais e imateriais historicamente constituídas. Sua compreensão oportuniza desmistificar os mitos, crenças, tradições e linguagens. Essas tradições, herdadas das comunidades dividem-se em duas linhas: formação do sujeito para cadeia produtiva individualista, precursora dos padrões de especialização do trabalho, modelo cada vez mais aceito pelo mercado internacional ou formação coletiva, atividade vinculada à produção cooperativa promotora do desenvolvimento comum. Entender o ethos torna-se condição sine qua non na promoção do desenvolvimento regional. Potencializar a essência coletiva resultará na participação política em decisões que envolvam os

\footnotetext{
${ }^{4}$ Segundo o dicionário de Filosofia de Abbagnano (2007, p. 792), o conceito significa: o mesmo que princípio. Ponto de partida, pensado como "o elemento constitutivo das coisas ou dos conhecimentos" Por exemplo: para Tales, a arché das coisas é a água.

${ }^{5}$ Originário das teorias de Pierre Bourdieu. Segundo a professora e pesquisadora Maria Amália de Almeida Cunha (2007, p. 504), os escritos de Bourdieu nessa área são resultados da colaboração de Jean-Claude Passeron na obra Les héritier (1964).
} 
interesses da área, fator de fomento para ascensão a uma sociedade igualitária nos direitos civis.

No "Capital Institucional", as entidades públicas e privadas representam a comunidade. Algumas características são comuns, como maleabilidade, eficácia e rapidez nas tomadas de decisões. Nesta perspectiva, as instituições são guiadas por um conjunto de regras, as quais devem corresponder ao espírito coletivo. As instituições representam, de forma articulada, o labor político na resolução de conflitos sociais ou de manutenção econômica.

$\mathrm{Na}$ sexta posição, o "Capital Psicossocial", extensivo ao capital cultural, estabelece relação do pensamento com a práxis. Ligado a sentimentos, recordações e vibrações familiares, o desafio visa aliar as premissas ideais à participação coletiva.. O pragmatismo é imanente no modelo, pois reaviva as noções de moral e ética estabelecidas no passado como fruto positivo a serem plantados na promoção das sociedades que virão.

Assim, o capital social contém traços que relacionam os atores sociais à cultura da confiança mútua, estimulando a associação e a cooperação através da constituição de ideias inovadoras. Segundo Boisier:

En términos simples, el capital social representa la predisposición a la ayuda
interpersonal basada en la confianza en que el 'o'tro' responderá de la
misma manera cuando sea requerido [...] La mayor parte de los autores que
escriben sobre capital social usan el concepto de sinergía para articular el
desarrollo capitalista con el desarrollo democrático mediante el surgimiento
de la asociatividad entre el sector público y el privado. Coleman, Putnam y
Fukuyama parecen dar mayor importancia a la asociatividad que a las
instituciones y organizaciones, como, por el contrario, se plantea en la
escuela institucionalista y, por lo menos Putnam ha sido acusado de relegar al
Estado a un papel totalmente secundario em el desarrollo, en buenas
cuentas, se ha querido ver un sesgo neoliberal en su análisis (1999, p. 47-48).

Esse capital baseia-se na expectativa dos grupos inseridos arcarem com os compromissos pré-estabelecidos entre as regiões. O diálogo mútuo é condição de acordos multilaterais para o trato econômico e limites regulatórios. Na forma em que se apresenta o capital, é dedutível a relação do modelo de produção primitivo (cooperativismo), com regras imanentes ao capitalismo em sua voracidade cotidiana, ou seja, o que está em jogo é produzir confiança entre as instituições para aumentar a competitividade e, consequentemente, maximizar os lucros. 
Dinamizar esta estrutura em uma lógica econômica hodierna, volátil e especulativa, apresenta-se como tarefa árdua: estimular a confiança, inserir noções ímpares implica em novas concepções de mundo. Essa discussão será apresentada no tópico: "Limites e potencialidades do desenvolvimento regional perante o processo de globalização".

O "Capital Cívico" é próprio às regiões democráticas, seus espaços são condizentes à participação popular. Exercer o patriotismo não se limita a amar o país, sua extensão deve ser vinculada a posicionamentos políticos, principalmente quando discutidas as expectativas de vida futura. Nessa etapa, o desenvolvimento torna-se condição de felicidade maior. O capital cívico implica confiança nos gestores públicos e comprometimento com o espaço comum.

Para finalizar, Boisier intitula o "Capital Humano", símbolo de conhecimentos, competências e habilidades imanentes aos indivíduos, resultado do processo educacional. Possibilitar a socialização e/ou desenvolvimento humano resultará na criação da consciência coletiva, capaz de atingir o píncaro das sociedades desenvolvidas. As utilizações de mecanismos próprios aos homens, como o domínio dos métodos filosóficos e científicos (conhecimento), fomentam o investimento em pesquisas que possam mensurar o potencial da região, bem como identificar a modalidade de capital que conduzirá o processo desenvolvimentista.

Em suma, os conceitos de Boisier elencados apresentam-se como estruturantes ao se discutir o desenvolvimento das regiões ou potenciais na sua busca. Sua visão é reconhecida pela comunidade acadêmica na maneira conceitual que apresenta o debate. Destarte, coloca-se no palco sua sustentabilidade em face da nova organização anacrônica do capitalismo financeiro globalizado, avessa a alguns desses conceitos apresentados. Essa discussão se compreende no próximo item.

\section{Limites e potencialidades do desenvolvimento perante o processo de globalização}

A questão do desenvolvimento angariou força após o término da Segunda Guerra Mundial e sua polissemia permite relacionar conceitos e críticas na imensidão das áreas do conhecimento. Com a prerrogativa de interpretar os 
acontecimentos políticos, econômicos e sociais que sucederam a guerra, dois teóricos de orientação marcadamente marxista (NEGRI; HARDT, 2006) procuram compreender os fatos e acontecimentos contemporâneos através do conceito "Império". Esforço necessário na interpretação das entidades internacionais, que surgiram com o objetivo de estimular o crescimento econômico, o desenvolvimento social e a reconstrução dos países atingidos pelo conflito.

Suas atividades se tornaram centrais quando oportunizaram empréstimos financeiros e de capital cognitivo às nações que almejavam fomentar a lógica capitalista. Dentre elas, podem-se citar o Fundo Monetário Internacional (FMI), a Organização das Nações Unidas (ONU), o Banco Internacional para Reconstrução e Desenvolvimento (BIRD), dentre outras. Segundo os referidos pensadores, a consolidação do Império liga-se a uma proposta transcendental colocada em prática:

[...] Hans Kelsen [...] propôs que o sistema jurídico internacional fosse concebido como a fonte suprema de toda formação e constituição jurídica nacional. Kelsen chegou a essa proposta por meio da análise da dinâmica formal de determinados arranjos de Estados. Os limites do Estado-nação, diz ele, criam obstáculos instransponíveis à realização da ideia de direito. [...] Ele pretendia ir além da lógica do poder em relações internacionais, de modo que "os Estados individuais possam ser vistos juridicamente como entidades de igual categoria" e um 'Estado mundial e universal' possa ser formado, organizado como 'comunidade universal superior aos Estados individuais, envolvendo-os a todos como uma capa'. (2006, p. 23)

Ao apreciar as diretrizes do "Império", Negri e Hardt criticaram seus pressupostos jurídicos, legitimidade e superioridade ao Estado-nação. Ao destituir a autonomia dos países, favorável à falta de democracia, em detrimento de decisões políticas e econômicas soberanas, reluzentes do paradigma econômico os pensadores apontam possíveis desentendimentos nas relações multilaterais, o que é 6. Sob outro viés, o "Império" nasce para manutenção de uma lógica centralizada, estratégica para os países desenvolvidos. Segundo Hard e Negri (2006, p. 11): "O

\footnotetext{
${ }^{6}$ Sob essa vertente, Zizek escreve em seu livro: Bem-vindos ao deserto do real - a relação de poder que os Estados Unidos da América (membro do "Império") estabeleceram com os "inimigos" após 11 de setembro: "[...] publicamente declarada a 'filosofia' oficial americana de política internacional [...] o poder militar americano deve permanecer 'fora de qualquer contestação' no futuro previsível; dado que hoje o principal inimigo é um fundamentalismo "irracional" que, ao contrário dos comunistas, carece de seu próprio povo, a América tem o direito a ataques preventivos, ou seja, a atacar países que ainda não representam uma ameaça clara aos Estados Unidos, mas que poderiam sê-lo no futuro, apesar de deverem procurar formar coalizões internacionais ad hoc para tais ataques, os EUA devem se reservar o direito de agir independentemente caso não consigam reunir o apoio internacional suficiente (2003, p. 10-11).
} 
império é a substância política que, de fato, regula essas permutas globais, o poder supremo que governa o mundo".

À luz destes pensadores, os processos de globalização, impulsionados pelas consequências do pós-guerra, emergem para unificação do capital e, consequentemente, para a aculturação ocidental. Frente à oferta, desponta os Estados Unidos da América (EUA), com o denominado "Way of Life", modelo pautado no fetichismo da mercadoria, do consumo, do acúmulo material, da liberdade política e econômica. O paradigma tornou-se justificativa para os ataques discursivos das sociedades ortodoxas do oriente; amparadas por um capitalismo primitivo e pelo fundamentalismo religioso, seus princípios são antinômicos; porém, diminutos perante o prazer mundano proporcionado hodiernamente. O desdobrar dos fatos resultou no ataque ao Word Trade Center (2001), alerta para demonstrar a falta de limites, quando se trata de proteger a religião mulçumana. ${ }^{7}$

Ao concentrar as decisões na racionalidade limitada do Soberano, engessamse as políticas governamentais regionais, visto que as agências multilaterais criam as medidas de ajustes através da padronização dos modelos políticos e econômicos. Frente a estes princípios, a emergência do desenvolvimento regional endógeno pode reafirmar as peculiaridades das regiões, o que coloca em jogo as estruturas de caráter transcendental, desvirtuando atitudes arbitrárias que desconhecem as bases do espaço geográfico, humano e cultural.

\begin{abstract}
O declínio da soberania dos Estados-nação, entretanto, não quer dizer que a soberania como tal esteja em declínio. Através das transformações contemporâneas, os controles políticos, as funções do Estado, os mecanismos reguladores continuaram a determinar o reino da produção e da permuta econômica e social. Nossa hipótese básica é que a soberania tomou nova forma, composta de uma série de organismos nacionais e supranacionais, unidos por uma lógica ou regra única. Esta nova forma global de economia é o que chamamos de Império (HARDT; NEGRI, 2006, p. 12).
\end{abstract}

As agências multilaterais que compõe o Império não obrigam o Estado-nação a associar-se; destarte, indiretamente, estes são conduzidos às regras da partida ${ }^{8}$. A condição para participar é seguir as leis auto-regulatórias do mercado liberal, evitar

\footnotetext{
${ }^{7}$ [...] o impacto dos aviões contra as torres do WTC são a obra de arte definitiva: pode-se entender o colapso das torres do WTC como a conclusão culminante da "paixão pelo real" da arte do século XX - os próprios "terroristas" não o fizeram primariamente visando provocar dano material real, mas pelo seu efeito espetacular (ZIZEK, 2003, p. 26).

${ }^{8}$ No caso, vale a máxima do governo Bush: "Ou você está conosco, ou você está contra nós".
} 
intervir ou colocar em risco a lógica da "confiança", fator que garante a estabilidade para as relações financeiras globais. Intervenções são benquistas, quando nascentes do soberano, dada a sua credibilidade e manutenção da égide sistemático-financeira volátil global em curso.

Os movimentos do Império não fluem para um centro territorial, suas expectativas são abrangentes, movem-se na direção do retorno a pangeia ${ }^{9}$, fator preponderante para alçar marcos regulatórios na economia, na saúde, no comércio e no espaço aéreo. A posição é estratégica para auxiliar no desenvolvimento econômico de algumas regiões ${ }^{10}$, quesito de ordem na promulgação dos interesses financeiros internacionais setorizados.

No caso brasileiro, é preciso levar em consideração que, entre as décadas de 40 e 60 do século XX, houve intenso debate de políticos, economistas, sociólogos, filósofos, geógrafos e historiadores, a fim de refletirem sobre as bases necessárias para a consolidação de um projeto de desenvolvimento econômico-nacional. $O$ movimento enalteceu o desenvolvimento a partir das potencialidades do país, riquezas naturais e capacidade de mobilização da sua força produtiva, auxiliados pela modernização da indústria de base. Sob essas expectativas, os resultados seriam os promotores desenvolvimentistas ${ }^{11}$, capazes de fortalecer a linha tênue do consumo entre as classes e o favorecimento da distribuição de renda.

Nos governos pertencentes ao regime militar, as propostas desenvolvimentistas estavam vinculadas ao financiamento externo, um dos fatores de composição da dívida externa com o Fundo Monetário Internacional (FMI). Nesta perspectiva, o modelo gerencial empresarial de tais governos se remete à lógica do capital internacional, constitutivo da dinâmica do Império.

A década de 80 ficou marcada pela queda do regime militar, juntamente com o reconhecimento dos limites desenvolvimentistas diante dos novos desafios políticos, econômicos e sociais que se apresentavam no país. O processo de abertura econômica, função instaurada pelo advento da globalização, no final do

9 Em grego, significa "toda a terra", teoria científica do início do século XX que relata que, há cerca de 200 milhões de anos, havia somente um continente, destarte a metáfora de um único sistema, sem distinção social, territorial, política e econômica.

${ }^{10}$ Desenvolvimento econômico sucede o crescimento econômico.

${ }^{11}$ Segundo a Teoria Geral do Emprego, do Juro e da Moeda de Keynes, os investimentos sustentam a linearidade do circuito econômico. A propensão natural do homem pelo consume resulta nos investimentos necessários ao aumento da produção, gerando emprego, renda e ciclo do capital. 
século passado, nos expôs as peripécias administrativas, exigidas pelas agências multilaterais, reguladoras da nova ordem mundial. Nesta perspectiva, o projeto nacional, pautado em princípios peculiares, tornou-se insustentável. Em primeiro lugar, pelo esvaziamento do Estado-nação; em segundo, por não reconhecer as particularidades regionais e levar em consideração os postulados do crescimento econômico como protagonista. ${ }^{12}$

O desenvolvimento regional é singular, em lugares como a região de Champanhe, na França; Tequila, no estado de Jalisco - México, eclodiram iniciativas endógenas e se estenderam ao mundo, oferecendo produtos particulares, que ostentam a nomenclatura regional, fator originário da confiança mútua e de aspectos culturais $^{13}$. Segundo os pressupostos de Francis Fukuyama (1996), os quais estão amparados em Boisier (1999), o sentimento de confiança é central no âmbito desenvolvimentista e interliga-se à condição cultural do povo. Dessa forma, a noção de familiaridade facilita o agir coletivo em prol da ação, enaltecendo a participação política nas tomadas de decisões, juntamente com as relações de solidariedade e cooperação.

Na generalidade dos fatos, o processo cultural está diretamente associado ao desenvolvimento ou à falta dele. O procedimento se conecta ao fazer histórico da localidade; um exemplo em voga são as regiões de matriz indígena, responsabilizadas historicamente pelos atrasos no desenvolvimento econômico. A condição se estrutura pela socialização diferenciada dos padrões consumistas, o que não significa a outorga de não desenvolvidos.

Segundo pesquisas realizadas pelo Cientista Social e pesquisador Walter Marcos Knasel Birkner e apresentadas no livro "Capital social em Santa Catarina" (2006), a visão pessimista acerca do egoísmo regional ou do descomprometimento social é intitulada pela população como fator decisivo no atraso econômico, político ou social local. Essa retórica extensiva da população, na tentativa de justificar o atraso desenvolvimentista, recai no senso comum. Segundo Birkner (2006, p. 153154), outros fatores primordiais devem ser levados em conta: "[...] fatores exógenos, como a falta de atenção do governo estadual. A falta de presença governamental é,

${ }^{12}$ Crítica pertinente é a fórmula utilizada para se mensurar o grau de desenvolvimento dos países, visto que se leva em consideração a média nacional.

${ }^{13}$ Essa modalidade potencializa a região economicamente, além de gerar empregos, fomenta outros setores, como o turismo local. 
no máximo, atribuída à própria ausência de representatividade regional e, por extensão, à incapacidade de uma articulação regional que supere os comportamentos isolacionistas".

Outro possível fator limitante do desenvolvimento decorre do sistema econômico vigente, movimento que reafirma a competição, eleva o darwinismo social e econômico, estimula a concorrência e a individualidade. Segundo os estudos de Birkner, a centralidade dos governos é um fator preponderante para a falta de desenvolvimento regional. Ao se tratar do Brasil, país com a quinta maior extensão territorial, implica reconhecer as diversidades climáticas, étnicas e culturais. À luz dos estudos de Roberto DaMatta, o Brasil pode ser classificado em duas faces, dois brasis ${ }^{14}$. Acrescente-se a isto, o fato de que cada região possui semelhanças, mas, sobretudo, diferenças na sua conformação geográfica e cultural.

Ainda segundo Birkner, as potencialidades do desenvolvimento regional se entrelaçam a dispositivos imanentes às sociedades civis organizadas. A necessidade em articular tarefas, entre o poder público e a sociedade civil, poderá apresentar resultados elevados na mensuração da qualidade de vida: fatores como distribuição de renda, saúde e educação, certamente, colocarão as regiões em cena.

\section{Construção política do desenvolvimento: participação social}

A participação social é direito assegurado pela Constituição Federal de 1988, tornando-se por excelência o fazer político do sujeito. A integralização das atividades que envolvem as primazias do Estado é o comprometimento necessário a envolverse na comunidade através das discussões sobre as políticas públicas. $\mathrm{O}$ ato político da sociedade civil pressiona os mecanismos de transparência estatal, garantindo a seguridade nas ações que beneficiam a coletividade.

\footnotetext{
14 Segundo Roberto DaMatta (1986, p.11), é possível dividir o país em duas vertentes, ou dito de outra maneira, um Brasil com b minúsculo sendo [...] apenas um objeto sem vida, autoconsciente ou pulsão interior, pedaço de coisa que morre e não tem a menor condição de se reproduzir como sistema; como, aliás, querem alguns teóricos sociais do século XIX, que viam na terra - um pedaço perdido de Portugal e da Europa - um conjunto doentio e condenado de raças que, misturando-se ao sabor da natureza exuberante e de um clima tropical, estariam fadadas à degeneração e à morte biológica, psicológica e social. Mas o Brasil com B maiúsculo é algo muito mais complexo. É país, cultura, local geográfico, fronteira, e território reconhecido internacionalmente, e também casa, pedaço de chão calçado com o calor de nossos corpos, lar memória e consciência de um lugar com o qual se tem uma ligação especial, única, totalmente sagrada.
} 


\begin{abstract}
A participação social passou a representar, em suas diversas modalidades, um elemento estruturante do Sistema Brasileiro de Proteção Social (SBPS). Sua análise oferece elementos relevantes para o debate atual sobre políticas públicas, seja no que se refere à sua institucionalização e execução, seja quanto ao enfrentamento das questões sociais (SILVA; JACCOUD; BEGHI, 2005, p. 1).
\end{abstract}

O processo democrático se torna primordial na participação popular, indispensável para os postulados do desenvolvimento. Essa discussão cria a hipótese da necessidade em maximizar o comprometimento e articular os espaços dos relacionamentos sociais. Segundo Birkner (2006), conhecer o vizinho pode ser uma medida imprescindível para discutir fatores que convergirão no desenvolvimento, como saber seu pensamento político, econômico e social, medida decisiva para o critério confiança, enaltecido por Fukuyama.

As relações familiares agregam essas discussões. O pequeno município de Abdon Batista, localizado na região serrana de Santa Catarina, com área territorial de $236 \mathrm{Km}^{2}$, população de 2.653 (IBGE, 2010), fundado no ano de 1989 (SEBRAE, 2013), é reconhecido pelo alto grau de parentesco da população. Cerca de $80 \%$ da população possui consanguinidade. A análise se afirma com os dados do Índice de Desenvolvimento Humano dos municípios brasileiros IDH-M -2010, ocupando 2.078은 lugar no Ranking composto por 5.565 lugares (PNUD, 2010).

Os critérios que mensuram o índice são compostos pela média dos quesitos: longevidade, renda e educação, divididos em cinco sessões na escala de zero a um: 1- Muito baixo desenvolvimento humano - escala de 0 a 0,499; 2 - Baixo desenvolvimento humano - escala de 0,500 a 0,599; 3 - Médio desenvolvimento humano - escala de 0,600 a 0,699; 4 - Alto desenvolvimento humano - escala de 0,700 a 0,799; e 5 - Muito alto desenvolvimento humano acima de 0,800.

Ainda nesta perspectiva, um dos critérios de Boisier para o Desenvolvimento Regional é a descentralização de renda; em Abdon Batista, o índice de renda é de 0,660, superior ao do município que se encontra na posição 1.191 (Paço do Lumiar MA). O município maranhense possui uma população superior a 78.000 habitantes, e essa distinção justifica-se pelo processo de colonização, carregado das imanências políticas, econômicas e culturais dos povos que desbravaram as terras.

Com a colonização de quatro famílias oriundas do Rio Grande do Sul, Abdon Batista alcançou sua emancipação político-administrativa somente em 1989, porém 
a jovialidade e traços culturais italianos ${ }^{15}$ foram primordiais para a elevação do IDH M. Sua condição política, fundamental na articulação do desenvolvimento, consolidou-se na confiança e cooperação, caso em que o parentesco auxilia.

O elemento da confiança, emergente nessas condições sociais, parece ter funcionado como espécie de 'leitmovit' nas iniciativas individuais. Cientes de que a realização de certos empreendimentos dependeria do auxílio de terceiros, os indivíduos foram em busca dessa cooperação (BIRKNER, 2006, p. 44).

A prática da confiança auxilia a constituição do Capital Social $O$ fundamento desse Capital é de caráter cultural. Sob tal enfoque, sua mensuração objetiva é algo discutível, senão improvável, mas o fato determinante é que, quando indivíduos agem coletivamente em função do bem comum, intensificam-se ações de ajuda mútua, fortalecendo os laços de confiança. Segundo Bandeira (1999, p.10):

[...] o capital social - que é composto por um conjunto de fatores de natureza cultural que aumenta a propensão dos atores sociais para a colaboração e para empreender ações coletivas - constitui-se em importante fator explicativo das diferenças regionais quanto ao nível de desenvolvimento $[\ldots]$

As peripécias exógenas são constituintes dos processos desenvolvimentistas como auxílio técnico e financeiro; experiências políticas ou mediação intelectual são capazes de direcionar a formação humana local para a aculturação cooperativista e confiança mútua, arraigadas ao Capital Social.

\begin{abstract}
A noção de capital social permite ver que os indivíduos não agem independentemente, que seus objetivos não são estabelecidos de maneira isolada e seus objetivos nem sempre são estritamente egoístas. Neste sentido, as estruturas sociais devem ser vistas como recursos, como um ativo de capital de que os indivíduos podem dispor. "O capital social, ensina Coleman (1990:302) não é uma entidade singular, mas uma variedade de diferentes entidades que possuem duas características em comum: consistem em algum aspecto de uma estrutura social e facilitam algumas ações dos indivíduos que estão no interior desta estrutura". O capital social, neste sentido, é produtivo, já que ele torna possível que se alcancem objetivos que não seriam atingidos na sua ausência (ABRAMOVAY, 2000, p. 4).
\end{abstract}

Desta forma, o capital social integra-se aos modelos desenvolvimentistas. Sua emergência favorece a criação de cooperativas e/ou associações, imanentes à óptica da descentralização de renda, geração de emprego, crescimento econômico,

${ }^{15}$ Essa tese ampara-se nos pressupostos do processo de socialização de Durkheim. Como a Europa (Itália) apresenta maior grau de desenvolvimento (IDH), seus descendentes tendem à herança dos aspectos pela convivência com os antecessores, externalizando as prerrogativas. 
bem como possível extensão da localidade aos palcos estaduais, nacional ou internacional. E ainda, amplia os espaços de participação política, melhora as condições para a atração do capital financeiro externo, que vislumbra na região um potencial para investimentos e atraem entidades que propiciam o desenvolvimento sob outras perspectivas.

\section{Desenvolvimento Regional Diante das políticas públicas}

O conceito de políticas públicas está enraizado na dinâmica e no sistema político do Estado brasileiro. Destarte, sua efetivação é colocada em jogo quando o processo governamental centraliza as decisões, soluções, medidas ou discussões, caminho às avessas da democracia.

As políticas públicas são resultado de ações do Estado ${ }^{16}$, originárias no mínimo de duas perspectivas, quais sejam: solução de problemáticas ou prevenção. As tomadas de decisões que as envolvem exigem racionalidade e participação, visto que, dentre as possíveis metodologias, as pesquisas conceituais, econômicas ou sociais visam mensurar os impactos e atacar as problemáticas com eficácia.

Reconhecidamente, as políticas públicas devem eclodir do pleito social, caso contrário, serão confundidas com tomadas de decisões governamentais, pois movimentações centralizadas e impositivas não são comumente aceitas pela população como medidas de políticas públicas. Segunda a professora e pesquisadora Marta Rodrigues (2010, p. 13):

Política pública é o processo pelo qual os diversos grupos que compõem a sociedade - cujos interesses, valores e objetivos são divergentes - tomam decisões coletivas, que condicionam o conjunto dessa sociedade. Quando decisões coletivas são tomadas, elas se convertem em algo a ser compartilhado, isto é, em uma política comum.

O governo tem papel decisivo na elaboração e execução das políticas públicas (desde que atendam às primazias); sob o locus da razão e mediação, visa solucionar as problemáticas em discussão, sob a expectativa de que as medidas paliativas são imprescindíveis para efeitos instantâneos, buscando ações urgentes

${ }^{16}$ Deve-se entender como resultado da demanda social, segundo pensamento do filósofo alemão Friedrich W. Hegel (1770-1831), oportunizando soluções as problemáticas que assolam a composição social em sua totalidade. 
para fatores que atravancam o desenvolvimento regional. Porém sua execução requer tomada de decisão e posicionamentos posteriores, contundentes para a resolução dos problemas e questões em curso.

Algumas catástrofes naturais no país, nos últimos anos, causaram calamidade pública; entretanto, a forma como se apresentaram permite especular sobre possível prevenção. No caso específico, trata-se das chuvas no Estado do Rio de Janeiro (2010 - 2011) e na cidade de Blumenau - Santa Catarina (2008). Discutir a situação é condição sociológica das constituições dos locais, ou seja, o primeiro fator é a habitação em áreas de risco, e o segundo, as ocupações ilegais ignoradas pelo poder público.

No caso do Rio de Janeiro, o que se conclui é que o preenchimento populacional em um morro que outrora serviu de "lixão" emerge com o fado do deslizamento. Outrossim, a construção de casas e o crescimento da cidade de Blumenau e região ao redor do Rio Itajaí-açu (área de alagamentos naturais) permitem que todo ano centenas de pessoas sejam remanejadas de suas casas devido às enchentes, outro fator dessas calamidades são as habitações próximas às encostas de morros. Seguramente, o caos social poderia e pode ser evitado, se racionalizado como política pública consistente, remanejando as famílias para locais adequados. Destarte, outras medidas de intervenção são possíveis e necessárias, entre elas, a adequada aplicação do Plano Diretor de ocupação do espaço urbano e rural dos municípios.

No contexto das políticas públicas, a política é entendida como um conjunto de procedimentos que expressam relações de poder e que se orienta à resolução de conflitos no que se refere aos bens públicos. Em uma palavra, a política implica a possibilidade de resolvermos conflitos de uma forma pacífica (RODRIGUES, 2010, p. 13, grifos do autor).

As políticas públicas são imanentes aos Estados democráticos, como conceituada, deve emergir da população. Ao aparelho governamental resta executar as tarefas, resolver os conflitos que assolam as localidades; dessa forma, a política pública torna-se parceira do desenvolvimento regional. Ao outorgar poder ao Estado na resolubilidade das problemáticas, deve-se levar em consideração a escassez de recursos humanos, fator que potencializa as demandas endógenas dos pressupostos de Boisier, porém não justifica a falta de racionalidade do Estado na 
condução das políticas públicas e do desenvolvimento regional, instância em que o capital social deve aliar-se ao poder público.

\section{Considerações finais}

O presente artigo discutiu algumas das possíveis dimensões do desenvolvimento regional, sob a perspectiva de Boisier, apresentando nove categorias de capital para possível desencadeamento de ações em sua direção. Em um primeiro resultado, deduz-se que as modalidades endógenas são fruto da dinâmica cultural, ou melhor, do processo de socialização dos sujeitos. Historicamente, as condições políticas, econômicas e sociais do Brasil favoreceram algumas regiões e destituíram a capacidade de desenvolvimento de outras. Seguramente, o modelo de produção utilizado (Brasil escravo) nos séculos que sucedem seu descobrimento, bem como a forma violenta como foram reprimidas iniciativas revoltosas, ao longo desta história, interferiram no modelo civilizatório brasileiro hodierno.

Segunda questão: trata-se de indagar a sustentabilidade dos pressupostos desenvolvimentistas. Em que medida seu alcance funcionará fora das diretrizes do mundo globalizado? Qual o grau de autonomia da região frente às dinâmicas globalizantes do "Império"?

Terceiro resultado: os fatores que alavancam o desenvolvimento regional ligam-se minimamente à política e à educação. Sob as expectativas do primeiro resultado, percebe-se que o processo cultural deve passar por uma transformação convergente, para alteração dos postulados que hoje imperam, como falta de confiança, abstenção da participação pública e social, falta de políticas públicas adequadas aos interesses e às necessidades locais e regionais.

Sob tais aspectos, a visão hegeliana constitui a sociedade em que vivemos. Segundo Hegel, o conceito de Filosofia da História, permite compreender o fenômeno moderno de organização. Sua leitura é cronológica, ou seja, nosso cotidiano é formado por pequenos fragmentos que se agruparam durante o passar dos tempos e findaram na organização social de hoje. Outra forma de compreender esse fenômeno é através da Dialética, ou melhor, do diálogo entre opostos, 
resultante de síntese, da qual convergirá em um novo diálogo social e, assim, ciclicamente.

Dessa forma, é possível afirmar que o tempo presente é o resultado de inúmeras manifestações populares, seguramente o pensamento coletivo exerce influência na direção dos interesses públicos. De outro lado, leia-se uma transformação constante, resultante da dialética. Assim, o mundo de hoje é o melhor para se viver, destarte outro modelo virá e será o ápice, como resultante do processo contínuo de nos constituirmos como seres políticos, cívicos.

Pensar o desenvolvimento regional é ampliar as alternativas, colocar em prática a racionalidade das instâncias que conformam o todo, sendo assim, a modalidade exógena auxilia a contemplar a lógica. O Estado, enquanto representação coletiva, pode protagonizar o desenvolvimento em regiões que não o conseguem fazer, na medida em que desejar. Essa ação não deve ser impositiva e, sim, relacional: a voz do povo é condição sine qua non, é a política pública o paradigma que fundamenta o desenvolvimento regional. Assim, desenvolvimento regional significa autonomia para a localidade; dessa maneira, a que se repensar o papel do Estado e sua capacidade de dinamização das regiões, como forma de otimizar e impulsionar ações que desencadeiem o desenvolvimento humano, social, político, cultural e, sobretudo, no âmbito regional.

\section{Referências}

ABRAMOVAY, Ricardo. O capital social dos territórios: repensando o desenvolvimento rural. Revista Economia Aplicada - n. 2, v. IV, p. 379-397, abr./jun., 2000.

AFFONSO, Rui de Britto Álvares. Descentralização e reforma do Estado: a Federação brasileira na encruzilhada. Economia e Sociedade, Campinas, p.127-152, jun. 2000.

BANDEIRA, Pedro. Participação, Articulação de Atores Sociais e Desenvolvimento Regional. Brasilia, 1999. Disponível em: <http://www.geodireito.com/_admDireito /Mod-biblioteca/Arquivos/texto_pedro_bandeira_n.630.pdf>. Acesso em: 5 jan. 2011.

BIRKNER, Walter Marcos Knaesel. Capital Social em Santa Catarina: o caso dos fóruns de desenvolvimento regional. Blumenal: Edifurb, 2006. 
BOISIER, Sergio. El desarrollo territorial a partir de la construccion de capital sinergetico. Revista Brasileira de Estudos Urbanos e Regionais, n. 2, nov. 1999.

. Em busca do esquivo desenvolvimento regional: entre a caixa-preta e o projeto político. Planejamento e Políticas Públicas, n. 13, 1996.

COMTE, Auguste. Curso de filosofia positiva. São Paulo: Abril Cultural, 1973

DAMATTA, Roberto. O que faz o brasil, Brasil? Rio de Janeiro: Rocco, 1986.

FUKUYAMA, F. Confiança: valores sociais e criação de prosperidade. Lisboa: Gradiva, 1996.

HARDT, Michael; NEGRI, Toni. Império. 8. ed. Rio de Janeiro: Record, 2006.

HEGEL, George Wilhelm Friedrich. Princípios da Filosofia do Direito. São Paulo: Martins Fontes, 1997. (Clássicos)

PROGRAMA DAS NAÇÕES UNIDAS PARA O DESENVOLVIMENTO. PNUD. Ranking dos Índices de desenvolvimento humano dos municípios brasileiros 2010 IDH - M. Disponível em: <http://www.pnud.org.br/arquivos/ranking-idhm-2010.pdf>. Acesso em: 7 jan. 2011.

RODRIGUES. Marta M. Assumpção. Políticas Públicas. São Paulo: Publifolha, 2010. Folha Explica.

ROVER. Oscar. Gestão política e desenvolvimento na região oeste de Santa Catarina. Cadernos do CEOM, ano 22, n. 30, 2009.

SEBRAE/SC. Santa Catarina em Números: Abdon Batista/Sebrae/SC. Florianópolis: Sebrae/SC, 2013.

SILVA, Frederico Barbosa da; JACCOUD, Luciana; BEGHI, Nathalie. Políticas sociais no Brasil: participação social, conselhos e parcerias. In: JACCOUD, Luciana et al. (Org.) Questão Social e Políticas Sociais no Brasil Contemporâneo, 2005. Disponível em:<http://www.ipea.gov.br/sites/000/2/livros/questaosocial/Cap_8.pdf>. Acesso em: 5 jan. 2011.

ZIZEK, Slavoj. Bem-vindo ao deserto do Real! Cinco ensaios sobre o 11 de Setembro e datas relacionadas. São Paulo : Boitempo, 2003. 